\title{
PERANCANGAN MEDIA PEMBELAJARAN MENGENAL ASMAUL HUSNA BERBASIS ANDROID
}

\author{
Yuventia Hesti Ningrum ${ }^{1}$, Dwi Dani Apriyani ${ }^{2}$ Zikriah $^{3}$ \\ Program Studi Informatika, Fakultas Teknik dan Ilmu Komputer, Universitas Indraprasta PGRI \\ Jl. Raya Tengah No. 80, Kelurahan Gedong, Pasar Rebo, Jakarta Timur \\ yuventiahn@gmail.com¹,dwidani12@gmail.com², qie.zikriah80@gmail.com ${ }^{3}$
}

\begin{abstract}
Abstrak.
Asmaul Husna merupakan Asma Allah yang Agung. Masih banyak masyarakat yang belum menghafal Asmaul Husna secara keseluruhan. Pengenalan Asmaul Husna saat ini masih banyak di dominasi oleh buku yang mana media seperti buku memiliki beberapa kekurangan seperti fisik yang mudah rusak dan kurang interaktif yang menyebabkan mudah bosan dan anak-anak di generasi milenial sekarang lebih tertarik menggunakan smartphone untuk bermain game dan bersosial media sehingga lebih senang menatap layar dibandingkan membaca buku. Tujuan Penelitian adalah untuk membangun aplikasi perangkat lunak berbasis android yang akan mempermudah dalam pembelajaran anak-anak dalam mengenal Asmaul Husna. Metode Penelitian yang digunakan adalah metode penelitian dan pengembangan (Research and Development). Metode pengumpulan data yang digunakan dalam penelitian ini adalah studi pustaka dan studi lapangan yang berupa observasi dan wawancara. Hasil dari penelitian ini dapat mempermudah anak-anak dalam belajar mengenal Asmaul Husna dengan menggunakan aplikasi media pembelajaran mengenal asmaul husna berbasis Android.
\end{abstract}

Kata kunci: Perancangan, Media Pembelajaran, Asmaul Husna, Android

\begin{abstract}
Asmaul Husna is the glorious names of Allah. There are still many people who have not memorized Asmaul Husna as a whole. The introduction of Asmaul Husna is still widely dominated by books where media such as books have some flaws such as pererous and less interactive physique that causes boredom and children in today's millennials are more interested in using smartphones to play games and social media so it is more fun to stare at the screen than to read books. The purpose of research is to build android-based software applications that will facilitate children's learning in getting to know Asmaul Husna. The research method used is research and development method. The data collection methods used in this study are library studies and field studies in the form of observations and interviews. The results of this study can make it easier for children to learn to know Asmaul Husna by using a learning media application to know Asmaul Husna based on Android.
\end{abstract}

Keyword: Designing, Learning Media, Asmaul Husna, Android

\section{PENDAHULUAN}

Asmaul Husna merupakan Asma Allah yang Agung. Dengan mempelajari Asmaul Husna kita dapat mengetahui nama-nama Allah yang baik, dan agung serta indah sesuai dengan sifat-sifatNya. Yang kita ketahui selama ini ada 99 nama, sesungguhnya para ulama berbeda pendapat mengenai jumlahnya. Ada yang berpendapat 100, 132, 200, 1000 bahkan 4000 bahkan mungkin lebih. Namun yang lebih penting dari semua itu bukanlah jumlahnya, melainkan Dzat-Nya, Dzat Allah yang harus kita kenali sebagai sang maha pencipta, maha penguasa, dan maha pemilik dari Alam Semesta dan seluruh isinya. Oleh sebab itu, pengenalan Asmaul Husna sangat penting untuk dipelajari dan ditanamkan sejak usia dini agar mereka dapat mengerti dan mengenali siapa yang telah menciptakan alam semesta beserta isinya (Ariyati, Sri \& Misriati, 2016).

Pengenalan Asmaul Husna saat ini masih banyak di dominasi oleh buku yang mana media seperti buku memiliki beberapa kekurangan seperti fisik yang mudah rusak dan kurang interaktif yang menyebabkan mudah bosan. Selain itu masih banyak masyarakat yang belum hafal Asmaul Husna secara keseluruhan karena rasa malas membaca, kesibukan, tidak dapat membaca (Farid \& Darmawan, 2017). Gempuran inovasi di bidang teknologi saat ini membuat masyarakat terutama generasi milenial lebih senang menatap layar gawai dibandingkan membaca buku. Dan juga anakanak generasi milenial sekarang lebih tertarik menggunakan smartphone untuk bermain game dan 
bersosial media. Sehingga diperlukan sebuah aplikasi pembelajaran Asmaul Husna yang dapat meningkatkan minat baca, mendengarkan, dan menghafal Asmaul Husna pada masyarakat.

Mengenal nama Allah adalah ilmu yang paling utama. Karena mulianya ilmu dilihat dari mulianya sesuatu yang dipelajari. Semakin mengenal Allah berarti semakin mencintai dan mengagungkanNya, juga semakin takut, berharap, ikhlas dalam beramal kepada-Nya. Semakin seseorang mengenal Allah, maka semakin ia berserah diri kepada Allah dan menjalani perintah dan menjauhi larangan dengan baik. Allah itu menyukai jika nama-Nya nampak bekasnya pada makhluk-Nya.

Seiring dengan berkembangnya media pembelajaran, seseorang cenderung memilih untuk memanfaatkan mobile device sebagai salah satu sarana pembelajaran. Salah satu perangkat yang saat ini paling banyak digunakan yaitu mobile phone dengan sistem operasi android. Jumlah pengguna android jauh lebih banyak dikarenakan saat ini sudah banyak smartphone android dengan harga yang terjangkau untuk masyarakat sehingga kemungkinan seseorang akan lebih banyak memanfaatkan sistem operasi android.

Perancangan merupakan penggambaran, perencanaan, pembuatan sketsa dari beberapa elemen yang terpisah kedalam satu kesatuan yang utuh dan berfungsi (Abdillah, Adhiguna, \& Sevtiana, 2017). Media pembelajaran adalah media yang membuat pesan-pesan atau infomasi yang bertujuan intruksional atau mengandung maksud-maksud pengajaran. Android adalah sistem operasi dan platform pemrograman yang dikembangkan oleh Google untuk ponsel cerdas dan perangkat seluler lainnya (seperti tablet). Android Studio merupakan sebuah software tools Integrated Development Environtment (IDE) untuk platform Android. Android Studio ini diluncurkan pada tanggal 16 Mei 2013 pada konferensi Google I/O oleh Produk Manajer Google, Ellie Powers (Yudhanto, 2018).

Tujuan penelitian ini adalah untuk menghasilkan aplikasi media pembelajaran mengenal Asmaul Husna berbasis Android untuk membantu kegiatan belajar anak - anak dalam mengenal dan memahami Asmaul Husna dengan dukungan tampilan yang menarik serta terdapat kuis interaktif untuk membantu evaluasi belajar.

Manfaat dari penelitian ini adalah proses pembelajaran mudah untuk diakses dan dioperasikan sehingga anak - anak dapat dengan mudah belajar mengenal dan memahami Asmaul Husna. Anak - anak diharapkan dapat menghafal Asmaul Husna dengan baik dan benar.

\section{PENELITIAN YANG RELEVAN}

Penelitian relevan dari (Ariyati, Sri \& Misriati, 2016), bagaimana merancang animasi interaktif pembelajaran Asmaul Husna bagi siswa taman kanak-kanak agar lebih menarik dan variatif sehingga minat siswa dalam belajar terus meningkat. Tujuan penelitian yang diharapkan adalah untuk menyampaikan informasi tentang Asmaul Husna melalui media Audio dan Visual kepada siswa taman kanak-kanak. Metode penelitian yang digunakan adalah metode model air terjun (waterfall). Hasil penelitiannya adalah Sebuah aplikasi yang diharapkan menjadi media pembelajaran yang interaktif, menarik, dan menambah semangat belajar dari siswa sehingga diharapkan ada perbaikan nilai dan pengetahuan siswa terkait Asmaul Husna.

Penelitian relevan dari (Farid \& Darmawan, 2017), bagaimana merancang aplikasi game pembelajaran Asmaul Husna yang interaktif dan dapat menarik kemabali minat ummat islam dalam menghafal Asmaul Husna. Tujuan penelitian yang diharapkan adalah untuk membuat sebuah aplikasi belajar Asmaul Husna yang interaktif disertai pengucapannya dan dilengkapi dengan Bahasa yang berbeda. Metode pengumpulan data yang digunakan adalah Observasi. Hasil penelitiannya adalah Sebuah aplikasi yang diharapkan mampu menarik kembali minat ummat islam untuk mempelajari Asmaul Husna.

\section{METODE PENELITIAN}

Metode yang digunakan yaitu Research and Development (R\&D). Metode R\&D adalah metode penelitian yang menghasilkan produk, produk yang dihasilkan berbentuk software ataupun hardware. Produknya berupa produk baru atau pengembangan dari suatu produk yang sudah ada. Langkah-langkah yang dilakukan dalam penelitian ini adalah menganalisa kebutuhan apa saja yang dibutuhkan untuk membuat aplikasi dengan cara melakukan studi pustaka, pengamatan terhadap anak - anak di TKQ - TPQ Masjid Jami Al - Muchlisin, dan wawancara ke salah satu pengajar untuk mendapatkan informasi yang dibutuhkan. Mencari data dan informasi melalui artikel, buku, dan internet untuk melengkapi proses analisa kebutuhan. Selanjutnya membuat rancangan 
tampilan, struktur, dan sistem aplikasi. Aplikasi yang telah selesai dibuat akan dilakukan pengujian aplikasi. Teknik pengumpulan data yang dipakai oleh peneliti dalam mengumpulkan data:

1. Studi Kepustakaan

Pengumpulan data dan informasi diperoleh dari kutipan-kutipan, jurnal, buku-buku, berbagai sumber data di internet serta hasil laporan dan bahan lainnya yang berkaitan dengan penelitian ini. Dari bahan-bahan tersebut diambil teori-teori yang dapat dijadikan landasan untuk menganalisa masalah yang ditemukan dalam penelitian.

2. Studi Lapangan

a. Pengamatan (Observasi)

Observasi merupakan cara atau metode menghimpun keterangan atau data yang dilakukan dengan mengadakan pengamatan dan pencatatan secara sistematis terhadap fenomena yang sedang dijadikan sasaran pengamatan (Mania, 2008).

b. Wawancara

Menurut hasil wawancara dengan Ustadz Hidayat selaku pengajar di TKQ-TPQ Masjid AlMuchlisin adalah bahwa asmaul husna harus diterapkan didalam diri manusia dan harus dikenalkan sejak usia dini, setelah anak memasuki sekolah dasar berikan pemahaman tentang asmaul husna. Sebelumnya orangtua juga harus paham mengenai apa itu asmaul husna. Lakukan penerapan asmaul husna di kehidupan sehari-hari dan ajarkan anak-anak untuk menerapkannya. Metode yang tepat untuk membuat anak-anak hafal adalah dengan menggunakan metode tikrar. Metode tikrar adalah metode yang biasa digunakan untuk menghafal Al-Qur'an. Cara kerja metode ini adalah anak harus membaca berulang-ulang dengan melihat tulisannya terlebih dahulu yang ingin dihafal misalnya dibaca sepuluh kali lalu setelah itu anak harus membaca tanpa melihat tulisan. Tiap hari harus diulang agar hafalan tersebut tidak hilang dari ingatan dan setiap sehabis shalat bacalah do'a dengan menyisipkan nama-nama Allah karena Allah menyukai jika Nama-Nya disebutkan dalam do'a hamba-Nya.

\section{Langkah Pengembangan Sistem}

Langkah-langkah pengembangan sistem diperlukan untuk merancang suatu sistem secara rinci berdasarkan atas hasil analisa sistem yang ada sehingga menghasilkan suatu model sistem yang baru. Berikut tahap-tahap yang dilakukan didalam membangun aplikasi Spesifikasi:

1. Analisis Kebutuhan

Langkah ini merupakan analisa terhadap kebutuhan sistem. Untuk melakukan sebuah penelitian perlu adanya tahap pengumpulan data. Tahap pengumpulan data yang digunakan adalah wawancara dan studi pustaka. Pada langkah ini juga akan menghasilkan data yang berhubungan dalam pembuatan aplikasi. Data ini akan menjadi acuan untuk peneliti konten apa saja yang diperlukan dalam membuat aplikasi pembelajaran Asmaul Husna ini.

2. Studi Kepustakaan

Peneliti melakukan studi kepustakaan berdasarkan referensi dan bertujuan untuk mempelajari dan memahami dasar teori yang berhubungan dengan analisa kebutuhan yang telah dilakukan. Selain itu peneliti juga melakukan studi dari berbagai media yang berupa buku-buku, artikelartikel baik di internet maupun media cetak yang berkaitan dengan edukasi anak usia dini untuk menunjang terselesaikannya penelitian ini.

3. Desain Sistem

Pada tahap ini dilakukan perancangan struktur data, karakteristik antarmuka, dan tampilan layer dari sistem yang akan dirancang agar menarik.

4. Perancangan Aplikasi

Dalam merancang sistem, flowchart menggambarkan suatu sistem secara global, termasuk input ke sistem, proses yang terjadi serta output-nya.

5. Pengujian Aplikasi

Apabila semua aplikasi telah selesai dibuat di dalam progam maka dilakukan proses pengujian, apakah program tersebut berfungsi sesuai dengan yang diharapkan. Supaya program tersebut dapat digunakan pada Instansi pendidikan yang membutuhkan. Apabila dalam proses terjadi error maka dapat kita lihat dimetode-metode sebelumnya. 


\section{HASIL DAN PEMBAHASAN}

Flowchart aplikasi Asmaul Husna yang dirancang dapat di gambarkan sebagai berikut:

\section{Flowchart Menu Utama}

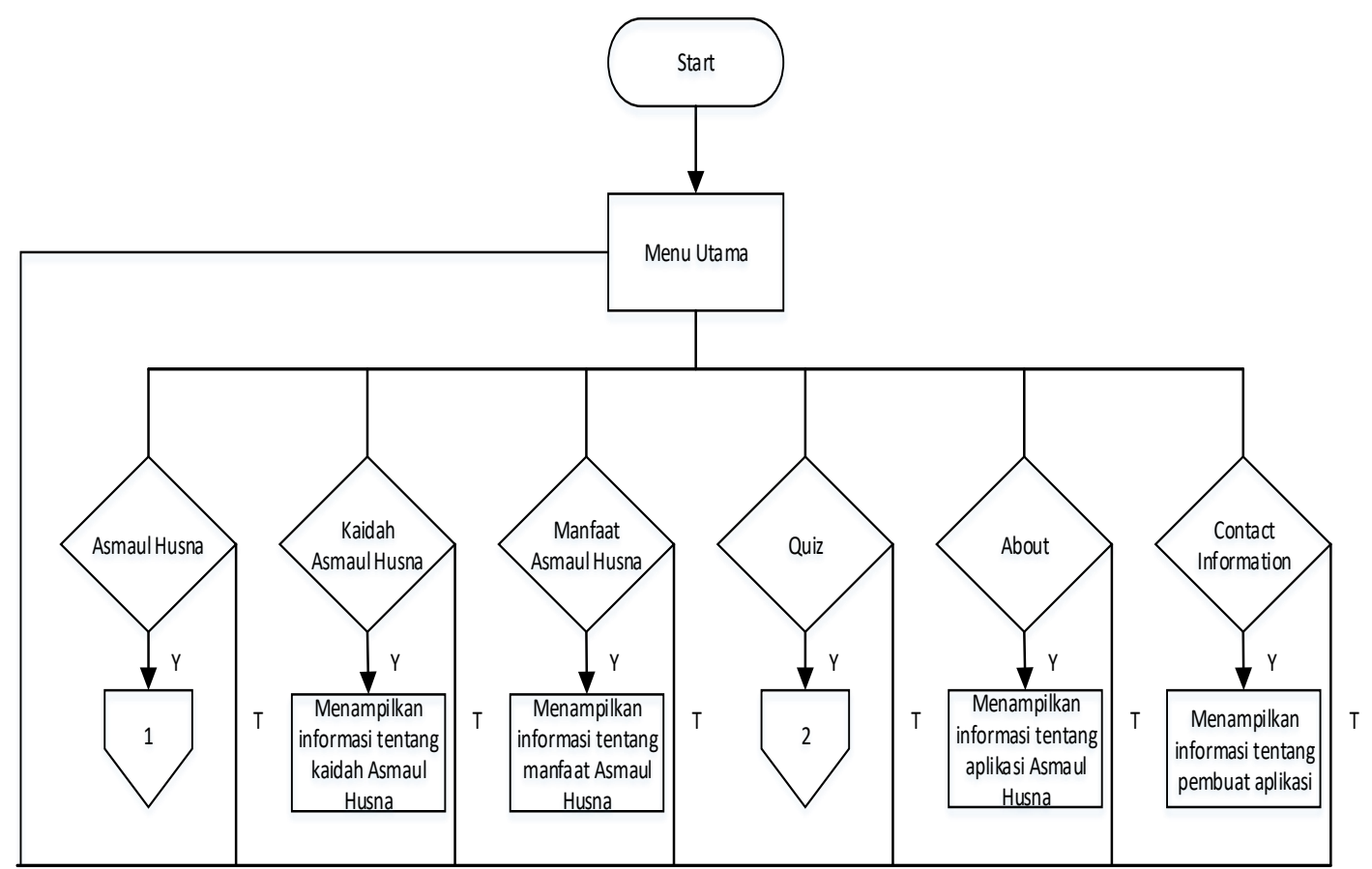

Gambar 1. Flowchart Menu Utama

\section{Flowchart Asmaul Husna}

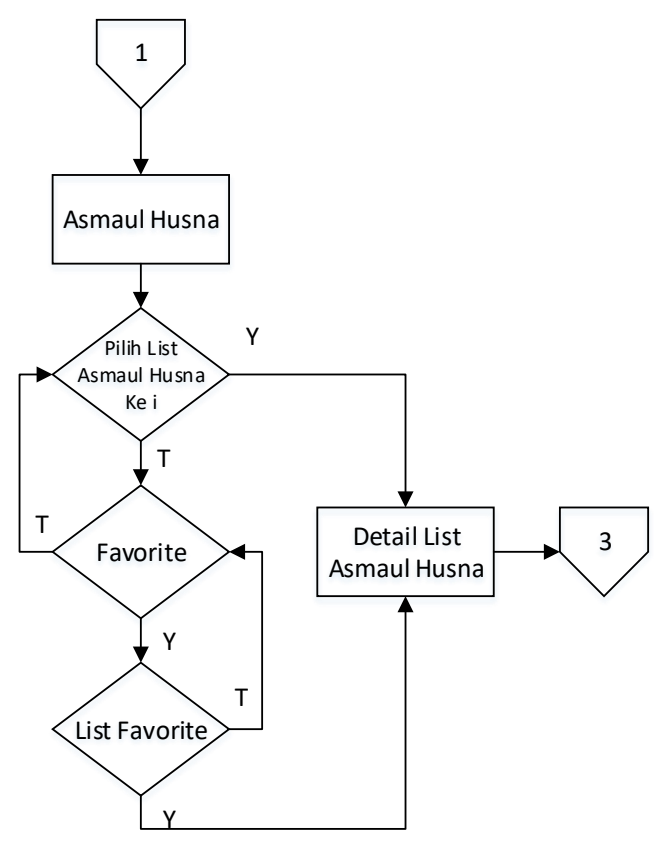

Gambar 2. Flowchart Asmaul Husna 


\section{Flowchart Detail List Asmaul Husna}

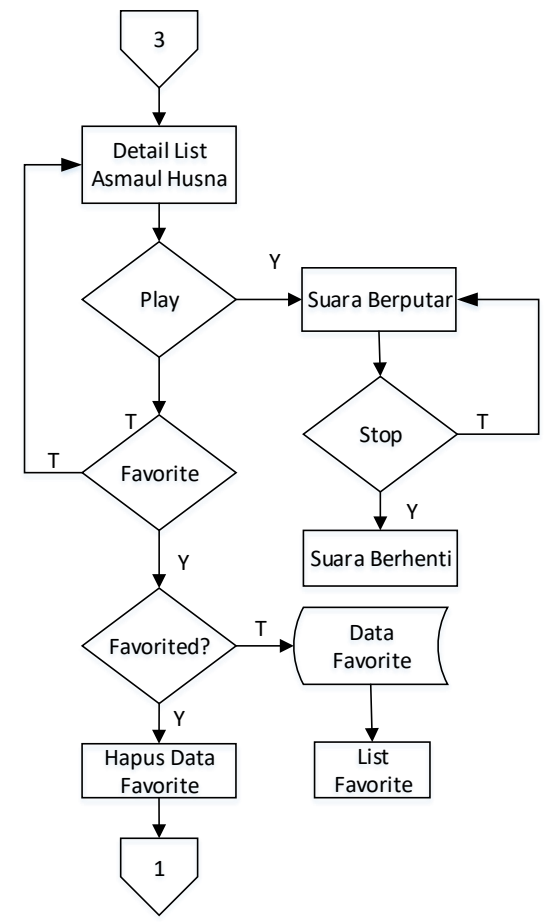

Gambar 3. Flowchart Detail List Asmaul Husna

\section{Flowchart Quiz}

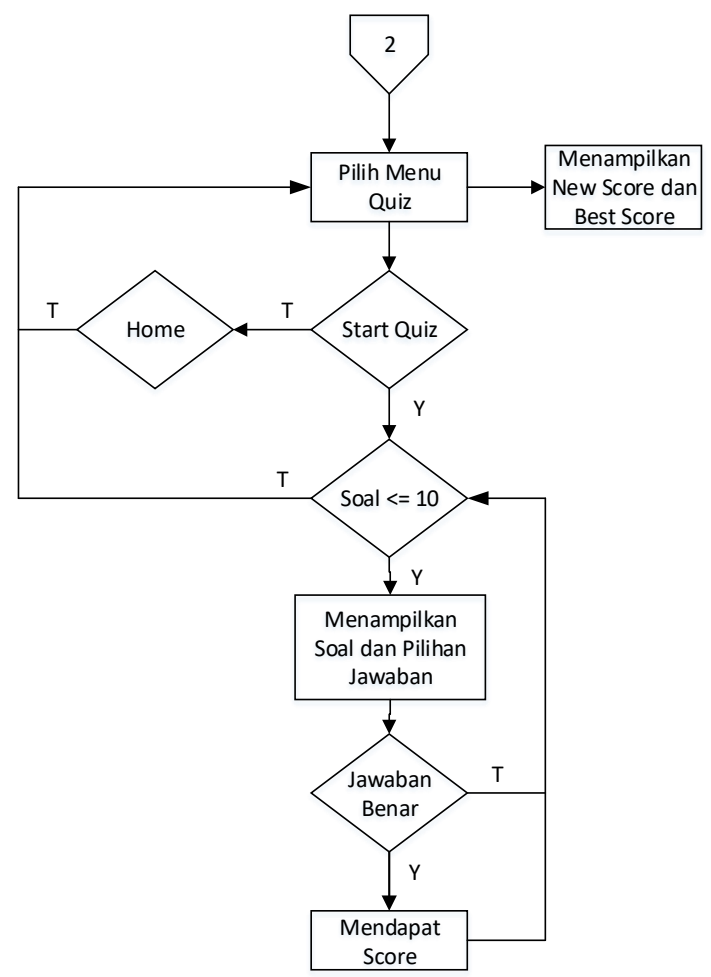

Gambar 4. Flowchart Quiz 


\section{Tampilan Aplikasi}

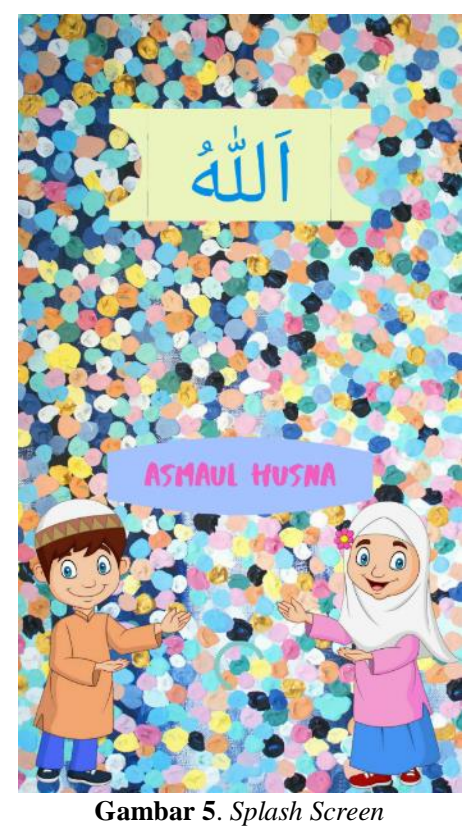

Splash screen adalah tampilan awal setelah membuka aplikasi yang tayang selama beberapa detik. Setelah splash screen selesai maka akan menampilkan menu utama.

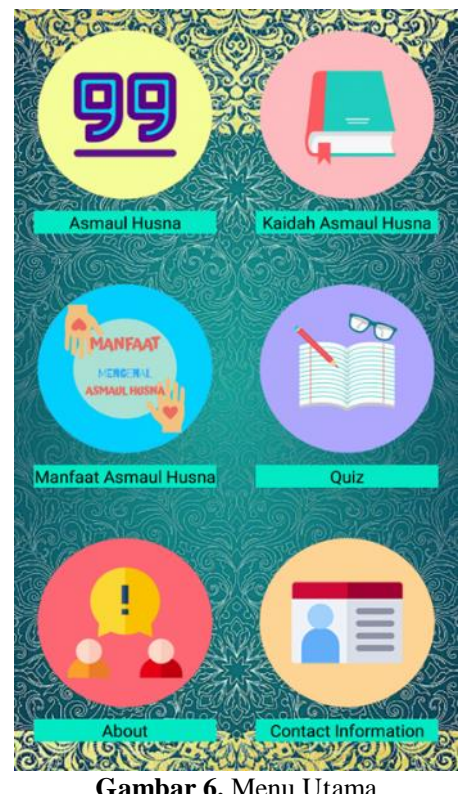

Menu utama adalah tampilan setelah splash screen dari aplikasi ini, terdapat enam button pada Menu Utama yaitu Asmaul Husna, Kaidah Asmaul Husna, Manfaat Asmaul Husna, Quiz, About, Contact Information. 


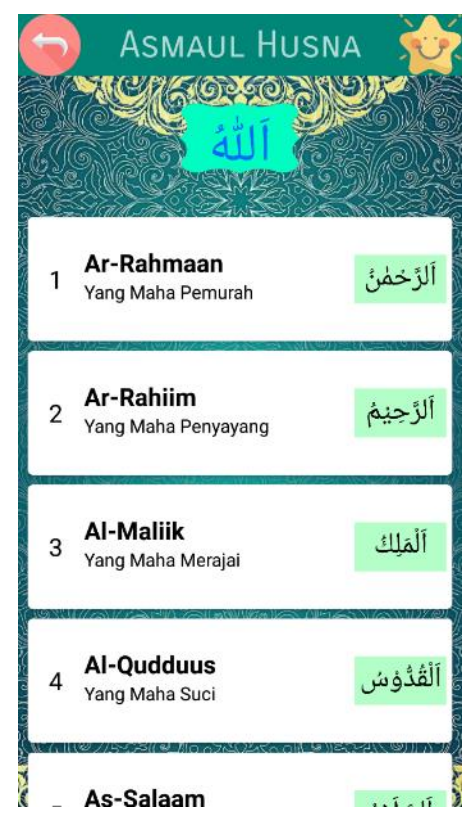

Gambar 7. Menu Asmaul Husna

Menampilkan nama - nama Allah (Asmaul Husna) dalam bentuk list, terdapat tombol Star untuk ke menu Favorite dan tombol Back untuk kembali.

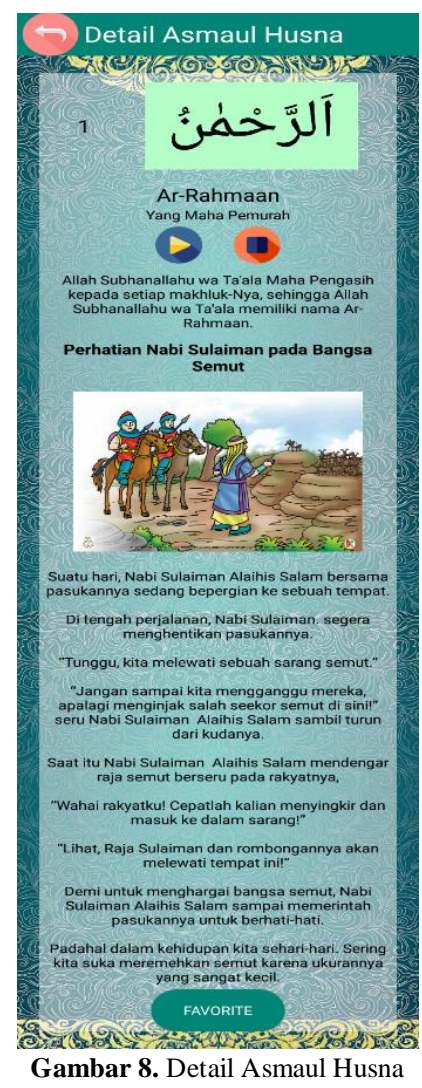

Merupakan menu yang ditampilkan setelah pengguna menekan salah satu asmaul husna di menu Asmaul Husna dan akan menampilkan detail mengenai asmaul husna yang dipilih. Terdapat tombol favorite yang dapat digunakan pengguna untuk memasukkan asmaul husna yang dipilih ke dalam data favorite. 


\section{SIMPULAN}

Dengan adanya aplikasi Asmaul Husna ini dapat membantu masyarakat terutama anak-anak dalam memanfaatkan gadget yang dimiliki untuk hal yang bermanfaat. Aplikasi ini mudah untuk dioperasikan dan diakses bagi pengguna sistem operasi Android. Anak-anak dapat menggunakannya untuk belajar mengenal dan memahami Asmaul Husna dengan baik dan benar. Kuis interaktif yang dapat membantu evaluasi belajar. Dengan aplikasi ini diharapkan anak-anak dapat dengan mudah menghafal Asmaul Husna.

\section{DAFTAR PUSTAKA}

Abdillah, F., Adhiguna, D., \& Sevtiana, A. (2017). Perancangan Video Profile sebagai Media Promosi STMIK CIC dengan Tehnik Motion Graphic Menggunakan Perangkat Lunak Komputer Graphic. Jurnal DIGIT.

Ariyati, Sri, \& Misriati, T. (2016). Perancangan animasi interaktif pembelajaran asmaul husna. Jurnal Teknik Komputer Amik Bsi, II(1), 116-121.

Farid, M., \& Darmawan, A. K. (2017). PERANCANGAN APLIKASI GAME PEMBELAJARAN ASMAUL HUSNA. 2017(Sehati), 53-57.

Mania, S. (2008). Observasi Sebagai Alat Evaluasi Dalam Dunia Pendidikan Dan Pengajaran. Lentera Pendidikan: Jurnal Ilmu Tarbiyah Dan Keguruan, 11(2), 220-233. https://doi.org/10.24252/lp.2008v11n2a7

Yudhanto, Y. \& W. A. (2018). Mudah Membuat dan Berbisnis Aplikasi Android dengan Android Studio. In Kompas Gramedia. 